\title{
Integrating Social Determinants in Decision-Making Processes for Health: Insights from Conceptual Frameworks - the 3-D Commission
}

\author{
Diogo Correia Martins • Opeyemi Babajide • Nason Maani • Salma M Abdalla • Eduardo \\ J. Gómez • Montira J. Pongsiri • Sheila Tlou • Gabriel Matthew Leung • Georges C. \\ Benjamin • Eric Goosby • Katie Dain • Jeanette Vega • Zahra Zeinali • Preslava Stoeva • \\ Sandro Galea • Jeffrey Sturchio • Nana A. Y. Twum-Danso
}

Accepted: 7 May 2021 / Published online: 3 September 2021

(C) The New York Academy of Medicine 2021

\begin{abstract}
The inclusion of social determinants of health offers a more comprehensive lens to fully appreciate and effectively address health. However, decision-makers across sectors still struggle to appropriately recognise and act upon these determinants, as illustrated by the ongoing COVID-19 pandemic. Consequently, improving the health of populations remains challenging. This paper seeks to draw insights from the literature to better understand decision-making processes affecting health
\end{abstract}

D. C. Martins • P. Stoeva

London School of Hygiene \& Tropical Medicine (LSHTM),

London, UK

D. C. Martins

e-mail: diogo.correiamartins.md@gmail.com

D. C. Martins · O. Babajide $\cdot$ N. Maani $\cdot$

S. M. Abdalla $(\bowtie) \cdot$ E. J. Gómez • M. J. Pongsiri · S. Tlou •

G. M. Leung • G. C. Benjamin • E. Goosby • K. Dain •

J. Vega $\cdot$ Z. Zeinali $\cdot$ S. Galea $\cdot$ J. Sturchio $\cdot$

N. A. Y. Twum-Danso

Rockefeller Foundation-Boston University 3-D Commission on

Determinants, Data, and Decision-making, Boston, USA

e-mail: abdallas@bu.edu

O. Babajide

e-mail: opeyemilatona@gmail.com

N. Maani

e-mail: nmaanihe@bu.edu

E. J. Gómez

e-mail: edg219@lehigh.edu

M. J. Pongsiri

e-mail: mpongsiri@gmail.com

S. Tlou and the potential to integrate data on social determinants. We summarised commonly cited conceptual approaches across all stages of the policy process, from agenda-setting to evaluation. Nine conceptual approaches were identified, including two frameworks, two models and five theories. From across the selected literature, it became clear that the context, the actors and the type of the health issue are critical variables in decision-making for health, a process that by nature is

e-mail: sheila.tlou.53@gmail.com

G. M. Leung

e-mail: gmleung@hku.hk

G. C. Benjamin

e-mail: Georges.benjamin@apha.org

E. Goosby

e-mail: Eric.goosby@ucsf.edu

K. Dain

e-mail:kdain@ncdalliance.org

J. Vega

e-mail: jeanvegamorales@gmail.com

Z. Zeinali

e-mail: zzeinal1@alumni.jh.edu

S. Galea

e-mail: sgalea@bu.edu

J. Sturchio

e-mail: jeff.sturchio@ rabinmartin.com

N. A. Y. Twum-Danso

e-mail: ntwumdanso@rockfound.org

N. Maani $\cdot$ S. M. Abdalla $\cdot$ S. Galea

Department of Epidemiology, Boston University School of Public Health, Boston, USA 
a dynamic and adaptable one. The majority of these conceptual approaches implicitly suggest a possible role for data on social determinants of health in decisionmaking. We suggest two main avenues to make the link more explicit: the use of data in giving health problems the appropriate visibility and credibility they require and the use of social determinants of health as a broader framing to more effectively attract the attention of a diverse group of decision-makers with the power to allocate resources. Social determinants of health present opportunities for decision-making, which can target modifiable factors influencing health-i.e. interventions

E. J. Gómez

Lehigh University, Bethlehem, USA

M. J. Pongsiri

Stockholm Environment Institute - Asia Centre, Bangkok, Thailand

S. Tlou

Nursing Now, Tuggerah, Australia

G. M. Leung

LKS Faculty of Medicine, The University of Hong Kong, Hong Kong, Hong Kong

G. C. Benjamin

American Public Health Association, Washington DC, USA

E. Goosby

Institute for Global Health Sciences, University of California, San Francisco, San Francisco, USA

K. Dain

NCD Alliance, Geneva, Switzerland

J. Vega

National Research and Development Agency (ANID Chile), Santiago, Chile

J. Sturchio

Rabin Martin, New York, USA

N. A. Y. Twum-Danso

The Rockefeller Foundation, New York, USA to improve or reduce risks to population health. Future work is needed to build on this review and propose an improved, people-centred and evidence-informed decision-making tool that strongly and explicitly integrates data on social determinants of health.

Keywords Decision-making - Social determinants of health $\cdot$ Data $\cdot$ Health policy $\cdot$ Political science

\section{Introduction}

The biomedical model has long been the dominant lens used to understand and act upon health and illness on a global scale [1]. However, the past few decades have seen growing recognition of the importance of a more comprehensive approach to fully appreciate and effectively address the causes of health, within and outside the healthcare sector [2]. This has become evident in the abundant literature on the population health impacts of the conditions in which people are born, grow, learn, live, work, play and age - known as the social determinants of health $[3,4]$.

Despite the growth of academic understanding of the importance of these social determinants of health, decision-makers do not always incorporate the role that social determinants play in shaping health. As a result, the social determinants of health are seldom considered in many decision-making processes. In turn, evidence increasingly suggests that when social determinants are poorly recognised or understood, decision-making processes that aim to improve the health of populations often fall short of properly addressing determinants of health; more than ever, political leaders and decisionmakers need to address these social determinants, as they are the root causes of inequity $[5,6]$. This has been made particularly clear during the ongoing COVID-19 pandemic as socially and economically patterned health outcomes have become manifest worldwide [7]. Integrating social determinants in decision-making for health is, therefore, more imperative now than ever [8].

There are several reasons why incorporating social determinants in health-related decision-making is challenging. First, decision-making processes in health are inherently complex and political [6]. Different actors operate in a variety of contexts, within and outside the health sector. These actors have the interest and the power to shape the content and the processes behind the development and implementation of policies that 
can, directly and indirectly, influence health $[9,10]$. The interests of these actors do not always align and may, sometimes, be at cross-purposes to the goal of promoting health [11]. For example, decision-making around subsidies for particular food products may be informed much more by economic concerns and the needs of food producers than by whether the food in question is health-producing for consumers.

Second, there is a paucity of agreed-upon tools that can help decision-makers recognise the value of measuring and acting on the social determinants of health. Existing conceptual approaches have not yet fully explored how we can use data on the social determinants of health to the end of informing decision-making processes. In addition, current tools tend to be more widely applied in retrospective analyses rather than predicting future scenarios. As a result, there is a knowledge gap in how the processes affecting population health can be analysed and improved throughout the stages of policymaking, ranging from planning to implementation, monitoring and evaluation.

Aiming to help address some of these challenges, we reviewed existing literature on decision-making in the social and political sciences in order to identify opportunities to integrate data on social determinants of health in decision-making. This article addresses two interconnected questions: What are the dominant explanations of the key elements of the decision-making processes affecting health? How can these existing conceptual approaches inform better decision-making around social determinants of health?

\section{Theoretical Background around Decision-Making and Health Policy-Making}

\section{Decision-Making}

Decision-making has been described as 'the process whereby an individual, group or organisation reaches conclusions about what future actions to pursue given a set of objectives and limits on available resources. This process can be iterative, involving issue-framing, intelligence-gathering, coming to conclusions and learning from experience' [12]. When applied to health, most scholars have focused on decision-making taking place in healthcare settings, which describe conclusions and actions taken by providers on behalf of patients, or shared between patients and providers [13].
Health Policy-Making

Decisions that have the potential to affect health of populations need, by definition, to extend beyond the clinical microsystem where most of the decisions are focused on the healthcare of individuals [14]. This, therefore, requires a shared understanding of what we mean by health policy-making. Buse, Mays and Walt [9] define health policy-making as 'courses of action (and inaction) that affect the set of institutions, organisations, services and funding arrangements of the health and the health care system', which include both the public and private sectors, as well as the actions of organisations external to the health system with a potential footprint on health (e.g. ministries of transport, agriculture or food and pharmaceutical industries).

Several policy tools, with reference to social/political sciences, have been developed to capture the highly complex set of elements of the health policy ecosystem. Most notably, the 'health policy triangle' by Walt and Gilson [15] is an example of a framework used by scholars to represent the context, actors, content and processes involved in health policy in a variety of settings (see Supplementary Information). Although this framework does not necessarily capture the fullness of the relationships between these elements, it remains a useful tool for those interested in influencing policymaking to think systematically about the different factors that might be involved.

When exploring the policy process, a commonly used approach is the 'stages heuristic', originally coined by Lasswell [16] (see Supplementary Information). This model represents a dynamic and continuous process, divided into a series of stages, from a starting point when policy-makers begin to think about a policy problem (agenda-setting) to a point in which a certain policy has been implemented and evaluated and policy-makers start deciding what to do next — which returns back to the agenda-setting phase. Despite its limitations [17], this model remains one of the most used ways of explaining and analysing the complexity of policy processes.

There are clear parallels between this approach to policy and decision-making processes, including the fact that several decision points are involved in each step of the way, especially during the initial agenda-setting and policy formulation stages. Given our goal of maximising opportunities for social determinants of health in decisionmaking phenomena, we focused on summarising the 
Table 1 Overview of included conceptual approaches in the final review against the key elements of the 'health policy' triangle (Walt and Gilson, 1994) [12]

\begin{tabular}{|c|c|c|c|c|c|}
\hline \multirow{2}{*}{$\begin{array}{l}\text { Stages } \\
\text { heuristic }\end{array}$} & \multirow[t]{2}{*}{ Conceptual approach } & \multicolumn{4}{|c|}{ 'Health policy triangle' } \\
\hline & & Context & Actors & Content & Process \\
\hline \multicolumn{6}{|l|}{ Frameworks } \\
\hline \multirow[t]{2}{*}{ Agenda-setting } & $\begin{array}{l}\text { Actor power, ideas, issue } \\
\text { characteristics, and } \\
\text { political contexts } \\
\text { framework (Shiffman and } \\
\text { Smith, 2007) [19] }\end{array}$ & $\begin{array}{l}\text { Supportive or } \\
\text { restrictive } \\
\text { political } \\
\text { context }\end{array}$ & $\begin{array}{l}\text { Strength and cohesion } \\
\text { of actors }\end{array}$ & $\begin{array}{l}\text { Issue characteristics } \\
\text { and power of ideas }\end{array}$ & $\begin{array}{l}\text { Nuanced } \\
\text { combination of } \\
\text { several factors } \\
\text { within these four } \\
\text { categories }\end{array}$ \\
\hline & $\begin{array}{l}\text { Advocacy coalition } \\
\text { framework (Sabatier, } \\
\text { 1988) [20] }\end{array}$ & $\begin{array}{l}\text { Policy } \\
\text { sub-systems } \\
\text { interacting for } \\
\text { long periods }\end{array}$ & $\begin{array}{l}\text { Advocacy coalitions } \\
\text { and policy brokers }\end{array}$ & $\begin{array}{l}\text { Agreement on } \\
\text { fundamental } \\
\text { policy positions } \\
\text { and objectives }\end{array}$ & $\begin{array}{l}\text { Equilibrium between } \\
\text { different } \\
\text { sub-systems, } \\
\text { reshaped by major } \\
\text { external shocks }\end{array}$ \\
\hline \multicolumn{6}{|l|}{ Models } \\
\hline \multirow[t]{2}{*}{ Agenda-setting } & $\begin{array}{l}\text { 'Legitimacy, feasibility and } \\
\text { support' model (Hall et al., } \\
\text { 1975) [21] }\end{array}$ & $\begin{array}{l}\text { Dependent on } \\
\text { available } \\
\text { resources }\end{array}$ & $\begin{array}{l}\text { Governments and } \\
\text { public }\end{array}$ & $\begin{array}{l}\text { Specific issues of } \\
\text { legitimate action } \\
\text { by governments }\end{array}$ & $\begin{array}{l}\text { High rank across } \\
\text { three elements } \\
\text { generates priority }\end{array}$ \\
\hline & $\begin{array}{l}\text { 'Policy windows' and three } \\
\text { 'streams' model (Kingdon, } \\
\text { 2010) [22] }\end{array}$ & $\begin{array}{l}\text { Political shifts } \\
\text { and major } \\
\text { events }\end{array}$ & Policy entrepreneurs & $\begin{array}{l}\text { Visibility of the issue } \\
\text { (scale and } \\
\text { significance) and } \\
\text { set of policy } \\
\text { alternatives }\end{array}$ & $\begin{array}{l}\text { Convergence of three } \\
\text { streams }\end{array}$ \\
\hline \multicolumn{6}{|l|}{ Theories } \\
\hline \multirow[t]{5}{*}{ All stages } & $\begin{array}{l}\text { Rationalism } \\
\text { (Simon, 1957) [23] }\end{array}$ & $\begin{array}{l}\text { May be } \\
\text { impractical to } \\
\text { collect data }\end{array}$ & $\begin{array}{l}\text { Who sets the goals can } \\
\text { be problematic }\end{array}$ & $\begin{array}{l}\text { Issues can be framed } \\
\text { in different ways }\end{array}$ & $\begin{array}{l}\text { Systematic process } \\
\text { that considers all } \\
\text { the options }\end{array}$ \\
\hline & $\begin{array}{l}\text { Bounded rationalism } \\
\text { (Simon, 1957) [23] }\end{array}$ & $\begin{array}{l}\text { Data, time and } \\
\text { resources are } \\
\text { limited }\end{array}$ & $\begin{array}{l}\text { Processing capacity is } \\
\text { limited }\end{array}$ & $\begin{array}{c}\text { Issues can be framed } \\
\text { in different ways }\end{array}$ & $\begin{array}{l}\text { Systematic but not } \\
\text { exhaustive process }\end{array}$ \\
\hline & $\begin{array}{l}\text { Incrementalism } \\
\text { (Lindblom, 1959) [24] }\end{array}$ & $\begin{array}{l}\text { Path dependency } \\
\text { and } \\
\text { institutional } \\
\text { stickiness } \\
\text { (conservative } \\
\text { bias) }\end{array}$ & $\begin{array}{l}\text { Decision-makers } \\
\text { 'muddle through' to } \\
\text { satisfy values at stake }\end{array}$ & $\begin{array}{l}\text { Does not explain } \\
\text { major policy } \\
\text { reforms }\end{array}$ & $\begin{array}{l}\text { Small adjustments to } \\
\text { status quo }\end{array}$ \\
\hline & $\begin{array}{l}\text { Mixed scanning } \\
\text { (Etzioni, 1967) [25] }\end{array}$ & $\begin{array}{l}\text { Combines the } \\
\text { idealist } \\
\text { rationalism } \\
\text { with realist } \\
\text { incremental- } \\
\text { ism }\end{array}$ & $\begin{array}{l}\text { Decision-makers at } \\
\text { different levels are } \\
\text { responsible for } \\
\text { fundamental or } \\
\text { routine decisions }\end{array}$ & $\begin{array}{l}\text { Broad analyses for } \\
\text { major decisions } \\
\text { and more detailed } \\
\text { ones for minor } \\
\text { decisions }\end{array}$ & $\begin{array}{l}\text { Difference between } \\
\text { major and minor } \\
\text { decisions }\end{array}$ \\
\hline & $\begin{array}{l}\text { Punctuated equilibrium } \\
\text { (Baumgartner and Jones, } \\
\text { 1991) [26] }\end{array}$ & $\begin{array}{l}\text { State of } \\
\text { equilibrium } \\
\text { altered by } \\
\text { external } \\
\text { shocks }\end{array}$ & Policy monopolies & $\begin{array}{l}\text { Understanding of the } \\
\text { problem and set of } \\
\text { policy options }\end{array}$ & $\begin{array}{l}\text { Influence of } \\
\text { emerging } \\
\text { coalitions or } \\
\text { changes in the } \\
\text { market conditions }\end{array}$ \\
\hline
\end{tabular}

most cited conceptual approaches across all stages of this policy process, from agenda-setting to evaluation. We included both frameworks and models that can help to map and visualise key components or variables in the decision-making process, as well as how these influence and interact with each other, and theories that can explain how decision-making phenomena take place and/or provide a way of predicting outcomes [18]. 


\section{Conceptual Approaches}

We identified nine conceptual approaches in the dominant social and political science literature that may be helpful in this context. Table 1 provides an overview of each conceptual approach, categorised by design, and mapped onto the 'health policy triangle' proposed by Walt and Gilson [15]. This categorisation was chosen because it offers a simplified representation of the different factors within each conceptual approach that can guide action for all for those interested in influencing policy-making in a practical and systematic way.

Two Main Frameworks Can Help Map Key Components or Variables in the Decision-Making Process

The work of Shiffman and Smith [19] attempts to explain why priority given to certain health issues differs across countries. This framework is based on four components that can either enable or block topics entering the policy agenda and be acted upon: the way the political context either promoted or restricted the support for the issue; the strength and cohesion of actors involved; the characteristics of the issue itself; and the power of the ideas used to portray the issue (see Supplementary Information). There are important lessons that can be extracted from this framework to better understand decision-making for health. First, the same key components influencing the priority given to different global health initiatives can be used to describe different decision-making ecosystems. Second, only some of these variables are influenced by objective data such as indicators of the scale of the problem and the cost-effectiveness of potential interventions to address it. A rationalist approach to decision-making would suggest that this type of data is central in deciding priorities and acting on them. However, a greater focus in this framework is given to social and political factors, including the broader political context, the relationships of different actors working in the field, and the way key individuals and agencies perceive and frame the issue. Looking at each one of these four components, there are also clear opportunities for data on social determinants of health to play a significant role in how these decisions are made. On the one hand, this could be in understanding what data is used to give visibility to the problem and credibility to the solutions. On the other hand, there is potential that certain topics can be more widely communicated and understood by the public in ways that may resonate more strongly with political leaders who control resources.

Sabatier's advocacy coalition framework [20] aims to describe the process of policy change within the context of sub-systems (see Supplementary Information). These policy sub-systems are ecosystems where communities or networks of actors interact with each other for long periods, leading to the dissemination and evaluation of policy ideas on a particular topic (e.g. mental health, HIV/AIDS). The limits of these subsystems are relatively stable, but from time to time, they are shaped by major external events. Within these subsystems, smaller groups of actors compete to advocate their solutions to policy problems. These are known as advocacy coalitions, bounded by a high level of agreement on core policy positions. To find feasible compromises between these positions advocated by the coalitions, policy brokers are understood as key actors, such as civil servants, working across the systems. This is particularly applicable in relatively open, decentralised political systems such as in the USA, and less where there is less interplay between advocacy coalitions, such as in low- and middle-income countries, where policymaking has traditionally been restricted to an elite, relatively small, segment of society. There are important parallels between ACF and how we could map decisionmaking ecosystems for the purposes of promoting action on the social determinants of health. In particular, the ACF describes the complexity of actors involved, connected by their core policy beliefs, and how a group of policy brokers can be fundamental in negotiating a compromise between differing viewpoints on the same policy issue. As with decision-making processes, there is a need to consider adaptability as implementation unfolds. Although this framework does not recognise the importance of data in the change process, there is a clear opportunity for social determinants of health to play a significant role in shaping the fundamental norms and beliefs of different advocacy coalitions. Examples may include the recent emergence of health coalitions in global environmental policy sub-systems, which strongly advocate that climate change is also a health issue and that therefore should inform decision-making around climate change. 
Two Key Models Can Help Understand How Different Components or Variables in Decision-Making Interact with and Influence Each Other

Hall et al. [21] propose that an issue will only get on to a government agenda when it ranks high in its legitimacy, feasibility and support. Further, Hall argues that governments have the right and obligation to intervene in response to specific issues (e.g. law and order, defence), but not others (e.g. private hospitals). In addition, technical and theoretical knowledge, resources, availability of skilled staff, administrative capacity and existence of necessary governmental infrastructure are fundamental to allow for the implementation of a particular policy. Last, there needs to be public support for the government concerning the policy issue. In practical terms, this model contends that before recognising and acting on specific issues, governments will estimate their likelihood of success based on these three principles. This model offers equally important principles to consider in the decision-making processes, particularly in the case of potentially contentious decisions. The degree of legitimacy differs greatly from country to country and changes over time. However, in times of perceived external threats, the public is generally more supportive of governments' action, even under conditions of uncertainty. These principles can be helpful to build trust between decision-makers and the public, particularly in advance of more complex decisions. There is an obvious opportunity for building data into this model, particularly to strengthen the case for the feasibility of different policy interventions. On the other hand, the complexity of social determinants of health can also become a hindering factor to the perceived feasibility of policy decisions.

Kingdon's model [22] aims to explain how policy entrepreneurs, in and outside governments, take advantage of policy windows to shift an issue onto the agenda of decision-makers. These windows emerge when three different and largely independent streams converge: problem, policy and politics (see Supplementary Information). The problem stream refers to the public perception of an issue which may or may not require government intervention; the policy stream considers the range of possible solutions; and the politics stream includes major events and changes in political will. This model provides several transferable insights. Similar to decision-making processes, different streams can influence to what extent one health issue will be on the government's agenda. The model emphasises the importance of policy entrepreneurs in bringing these three streams together when striving to build a consensus within government for reform. Although the meeting of these different streams cannot be easily engineered or predicted, policy entrepreneurs can use data on social determinants of health to further emphasise the importance of a particular piece of legislation. These particular streams are concerned with the availability of indicators of scale and significance of an issue which give it a real and perceived visibility, as well as the understanding of alternative policy solutions and their acceptability and feasibility.

Five Theories Can Help Us Explain How

Decision-Making Processes Take Place and Provide a Way of Predicting Outcomes

Simon [23] argues that to achieve their desired outcomes, organisations should make decisions based on a rational approach. This rational process produces a series of alternative options to address a certain policy goal, which emerges from a logical sequence of steps: define the problem; clarify and rank the goals and values of the decision-makers involved; list all alternative strategies to achieve their goal; comprehensively analyse the impact and unintended consequences of each course of action; and compare options and decide on which options may be the most cost-beneficial. However, this approach can easily become too idealistic and impractical when an urgent decision is needed. On the other hand, bounded rationalism recognises the inherent limitation of data, time and processing capacity within decision-making processes. In this context, Simon coined the concept of satisficing, a combination of satisfying and sufficing, defined as a decision-making strategy that prioritises meeting criteria for adequacy instead of finding the perfect solution. While decisions are often assumed to be made rationally, real-life scenarios are often far from ideal. Time is limited, resources are scarce and in need of prioritisation, and data are often missing. This means that decisions are frequently made under enormous pressure and uncertainty. The bounded rationalism theory by Simon offers a unique guide that decision-makers can strive for in more realistic scenarios, by proposing structured, evidence- 
informed and logical processes to decide on adequate policy solutions, while accepting the limitations of the inputs and outputs of the process itself. In parallel, this process highlights exceptional points in the process where data on social determinants can mitigate the risks of imperfect decision-making, particularly in the early stages of problem definition and weighting the criteria for decision-making.

Lindblom [24] notes that decisions are made incrementally, by small adjustments to the status quo and considering political realities. He defends this approach by noting that decision-makers test political waters before deciding whether to pursue a course of action or not. Both path dependency and institutional stickiness may explain a certain conservative bias of decisionmakers and their institutions, in that they limit the range of courses of action available, which are naturally influenced by previous decisions. The main focus of this approach is on securing the agreement of the various interests involved and satisfaction of the values at stake. The work of Lindblom helps explain why major policy reforms have historically been prevented given the natural resistance to change of many institutions in decision-making. The onus of this approach is on being pragmatic. It offers a way forward in decision-making when the topic is controversial, technical information is missing, there is little consensus about what solutions to prioritise and little appetite for risk or innovation.

Etzioni [25] combines the unrealistic idealism of the rational approach and the conservative realism of the incremental theories in his mixed scanning theory. $\mathrm{He}$ proposes a distinction between major and minor decisions. While for major decisions, decision-makers should focus on broad analyses of the issue, for minor decisions that either lead up to or follow-up from major decisions, more detailed analyses of the policy options should be considered. Despite the potentially unclear distinction between fundamental and routine decisions, the work of Etzioni provides relevant guidance for adapting decision-making processes according to their potential impact. In particular, it suggests that actors involved in each can mitigate the risks of setting unrealistic expectations associated with rationalism by limiting the amount of detail required for major decisions, while a broader view can overcome the conservative bias of incrementalism by reflecting on the long-term policy options for minor decisions.

The punctuated equilibrium theory of Baumgartner and Jones [26] helps to explain that decision-making processes are often characterised by long periods of stability which can be shocked by abrupt adjustments, policy reversals and reforms. These periods of stability are often maintained by policy monopolies or governing elites who can convincingly articulate a view of a problem and establish a set of policy responses and political institutions to address it. However, there are times when this equilibrium is punctuated by external shocks, as a result of new governing coalitions or major changes in market conditions, bringing about new far-reaching change. The main contribution of the work of Baumgartner and Jones is the understanding that decision-making processes vary over time and can be disrupted by unexpected events that may destabilise the foundations of governing institutions. These periods of stability and disruption can pose both risks and opportunities for major policy reforms and changes in the decisionmaking ecosystem.

\section{Discussion}

We identified nine conceptual approaches relevant to decision-making for health; these included two frameworks [19, 20], two models [21, 22] and five theories [23-26]. Four approaches focused on agenda-setting [19-22], and five focused on explaining the likelihood of different outcomes in the health policy process, relevant to all stages of the policy cycle [23-26]. Each one of these tools carries important insights that shed light on the complexity of the health policy environment and, by association, the decision-making ecosystems and pave the way for better integration of data on social determinants of health. These approaches also offer answers to the two questions we posed in this paper.

\section{What Are the Dominant Explanations of the Key Elements of the Decision-Making Processes Affecting Health?}

We identified several common elements that are important to the decision-making processes that affect health.

First, context is an undeniable factor in decisionmaking for health. Not only most decisions across the policy cycle are made under tremendous uncertainty, as explained by Simon [23], but most governments will have to consider whether or not they have the legitimacy and the public support to act before they even start, as described by Hall et al. [21] This may help explain specific scenarios of institutional inertia or perceived 
inaction of political leaders [24] in times of greater stability. This is particularly true when external societal and political shocks are absent or when contentious issues arise [22, 26].

Second, actors are consistently a central piece in the decision-making puzzle. Several conceptual approaches highlight that it is not only crucial who they are and how they organise themselves, but how cohesively they work together [19]. For example, Kingdon describes the importance of policy entrepreneurs, while Baumgartner and Jones refer to policy monopolies [26], who can capitalise on policy windows to accelerate policy decisions [22]. Sabatier famously defends that 'coalition' groups and 'policy brokers' are both essential to maintaining the balance in policy eco-systems [20].

Third, the content or nature of the health issue in itself may predict divergent outcomes in the decisionmaking process. On the one hand, objective indicators of the scale and significance of the problem and potential solutions play an important role, as described across several frameworks, models and theories [19, 21-23]. On the other, the way health issues are portrayed and resonate with the values of decision-makers is equally vital, if not more important [19, 22-24]. Both Shiffman and Smith [19] and Kingdon [22] point out that the greater the complexity of the problem, the less likely it is to succeed both in terms of capturing the attention of decision-makers and gaining support from the public.

Fourth, the process of decision-making for health is a dynamic and adaptable one, as mirrored in several theories. While Simon [23] and Lindblom [24] argue that rationalism and incrementalism are, respectively, both valid approaches to decision-making, Etzioni [25] defends that it is possible to find a middle-ground between these two, according to the type of decision necessary. In this regard, 'satisficing' is perhaps the concept in bounded-rationalism most helpful for decision-makers wanting to balance in practice gathering enough data to make the right decisions on time [23].

How Can These Existing Conceptual Approaches Inform Better Decision-Making Around Social Determinants of Health?

These frameworks also highlighted links and opportunities to better integrate data on social determinants of health in decision-making. While the majority of the conceptual approaches suggest a role for data on social determinants of health in decision-making [19-23], this link remains rather implicit. We suggest that on consideration of these frameworks, there are three main opportunities to make the link more explicit emerge. First, the use of data can give health problems and potential solutions the appropriate visibility and credibility they require. Second, the use of social determinants of health as a broader framing can more effectively attract the attention of a diverse group of decision-makers with the power to allocate resources. Third, social determinants of health present opportunities for decision-making action, which can target modifiable factors influencing health-i.e. interventions to improve or reduce risks to population health. However, if used inappropriately, the social determinants of health lens may have a counterproductive effect by increasing the perceived complexity problem and necessary policy solutions among key audiences, such as governments and the public.

\section{Conclusion}

This review provides a succinct overview of the most commonly used conceptual approaches to decisionmaking for health. This review points to actionable products that can lead to a commonly agreed approach that can help decision-makers recognise the value of measuring and acting on the social determinants of health.

Although the selected conceptual approaches have historically been widely used in retrospective analytical exercises, there are practical lessons that can be learned from them in planning scenarios ahead and predicting population health outcomes.

Future work is needed to build on this review, expand on the selection of conceptual approaches where relevant and consult with decision-making experts and their constituencies to jointly propose an improved, peoplecentred and evidence-informed decision-making tool that strongly and explicitly integrates data on social determinants of health, validated for different contexts and across sectors.

Acknowledgement We thank Leona Ofei for her support with formatting. The Rockefeller Foundation-Boston University 3-D Commission (Grant number: 2019 HTH 024). 


\section{References}

1. Abdalla SM, Solomon H, Trinquart L, Galea S. What is considered as global health scholarship? A metaknowledge analysis of global health journals and definitions. BMJ Glob Health. 2020;5(10):e002884. https://doi. org/10.1136/bmjgh-2020-002884.

2. Farre A, Rapley T. The new old (and old new) medical model: four decades navigating the biomedical and psychosocial understandings of health and illness. Healthcare. 2017;5(4):88. https://doi.org/10.3390/healthcare5040088.

3. Black D. Inequalities in health: report of a research working group: Department of Health and Social Security; 1980.

4. Marmot M. Fair Society Healthy Lives (The Marmot Review). London; 2010.

5. Guy TV, Kárný M, Wolpert DH. Decision Making with Imperfect Decision Makers. In: Intelligent Systems Reference Library: Springer-Verlag Berlin, Heidelberg; 2012.

6. Dawes DE. The political determinants of health: Johns Hopkins University Press; Baltimore, MD; 2020.

7. Abrams EM, Szefler SJ. COVID-19 and the impact of social determinants of health. Lancet Respir Med. 2020;8(7):659-61. https://doi.org/10.1016/S2213-2600(20)30234-4.

8. Galea S, Abdalla SM, Sturchio JL. Social determinants of health, data science, and decision-making: forging a transdisciplinary synthesis. PLoS Med. 2020;17(6):e1003174. https://doi.org/10.1371/journal.pmed.1003174.

9. Buse K, Mays N, Walt G. Making health policy. Second ed: McGraw-Hill Education; Maidenhead; 2012.

10. Gómez EJ. Geopolitics in health: confronting obesity, AIDS, and tuberculosis in the emerging BRICS economies: Johns Hopkins University Press; Baltimore, MD; 2017.

11. Blendon RJ, Steelfisher GK. Commentary: understanding the underlying politics of health care policy decision making. Health Serv Res. 2009;44(4):1137-43. https://doi. org/10.1111/j.1475-6773.2009.00979.x.

12. Schoemaker PJH, Russo JE. Decision-making: Palgrave Macmillan; 2014. https://doi.org/10.1057 /9781137294678.0160.

13. Kaplan RM, Frosch DL. Decision making in medicine and health care. Annu Rev Clin Psychol. 2005;1:525-56. https://doi.org/10.1146/annurev.clinpsy.1.102803.144118.
14. Likosky DS. Clinical microsystems: a critical framework for crossing the quality chasm. J Extra Corpor Technol. 2014;46(1):33-7.

15. Walt G, Gilson L. Reforming the health sector in developing countries: the central role of policy analysis. Health Policy Plan. 1994;9(4):353-70. https://doi.org/10.1093 /heapol/9.4.353.

16. Lasswell $\mathrm{H}$. The decision process: seven categories of functional analysis: Bureau of Governmental Research College of Business and Public Administration University of Maryland; College Park, MD; 1956.

17. Weible CM, Sabatier PA, editors. Theories of the Policy Process: Fourth edition, Routledge; New York, NY; 2018.

18. Nilsen P. Making sense of implementation theories, models and frameworks. Implement Sci. 2015;10(1):53. https://doi. org/10.1186/s13012-015-0242-0.

19. Shiffman J, Smith S. Generation of political priority for global health initiatives: a framework and case study of maternal mortality. Lancet. 2007;370(9595):1370-9. https://doi.org/10.1016/S0140-6736(07)61579-7.

20. Sabatier PA. An advocacy coalition framework of policy change and the role of policy-oriented learning therein. Policy Sci. 1988;21(2-3):129-68. https://doi.org/10.1007 /BF00136406.

21. Hall P, Land H, Parker R, Webb A. Change, Choice and Conflict in Social Policy: Ashgate Publishing Company; London; 1975.

22. Kingdon JW. Agendas, Alternatives and Public Policies. 2nd ed: Longman; Boston, MA; 2010.

23. Simon HA. Models of man; Social and Rational: Wiley; New York, NY; 1957.

24. Lindblom CE. The Science of "Muddling Through." Public Adm Rev. 1959;19(2):79. https://doi.org/10.2307/973677.

25. Etzioni A. Mixed-scanning: a "third" approach to decisionmaking. Public Adm Rev. 1967;27(5):385. https://doi. org/10.2307/973394.

26. Baumgartner FR, Jones BD. Agenda dynamics and policy subsystems. J Polit. 1991;53(4):1044-74. https://doi. org/10.2307/2131866.

Publisher's Note Springer Nature remains neutral with regard to jurisdictional claims in published maps and institutional affiliations. 